\title{
CONCEPTS
}

\section{Venomous snake husbandry in Thailand}

\author{
LAWAN CHANHOME, DVM; PIBOON JINTAKUNE, MSc; HENRY WILDE, MD, FACP; MEREL J. COX, MS \\ From the Queen Saovabha Memorial Institute, Thai Red Cross Society, Bangkok, Thailand (Dr Chanhome, Mr Jintakune, and Dr Wilde), \\ and the Division of Mathematics and Natural Science, Penn State, Altoona, Altoona, PA (Mr Cox).
}

\begin{abstract}
A captive breeding program for venomous Thai snakes was established at the Queen Saovabha Memorial Institute at Bangkok, Thailand. This was necessary to secure a stable, healthy, and speciesconfirmed source of snake venom for antivenom production. In 1994, wild-caught specimens were collected, sexed, quarantined, and housed appropriately. All data in this report, with the exclusion of Table 6, were collected from 1994 to 1997. Two species were bred successfully in captivity to date during this study period. Although captive breeding has not yet been achieved with all species and subspecies, our early success was encouraging.
\end{abstract}

Key words: snake husbandry, venomous snakes of Thailand, snake antivenom manufacture

\section{Introduction}

Thailand has at least 175 species and subspecies of snakes, of which 48 are venomous. ${ }^{1}$ Some live in close proximity to humans and cause human morbidity and fatalities. ${ }^{2}$ The Thai Red Cross Snake Farm was founded in 1923 and is currently located on the premises of the Queen Saovabha Memorial Institute of the Thai Red Cross Society (QSMI). The Snake Farm's activities are to keep medically important snakes for extraction of venom and for the production of antivenom; to perform research in the fields of snake venom toxicology, pathophysiology of envenoming, and biology of snakes; and to educate the public about snake ecology and natural behavior. The farm is open daily to demonstrate feeding as well as extraction of venom, and visitors are welcome. Queen Saovabha Memorial Institute currently produces antivenoms for the Siamese cobra (Naja kaouthia), king cobra (Ophiophagus hannah), banded krait (Bungarus fasciatus), Siamese Russell viper (Daboia russelii siamensis), Malayan pit viper (Calloselasma rhodostoma), and the whitelipped green pit viper (Trimeresurus albolabris). Antivenom for the Siamese cobra also neutralizes the venom of the Indochinese spitting cobra. ${ }^{3}$ That of the whitelipped green pit viper neutralizes the venom of several other species of Trimeresurus. This subject has not yet been fully elucidated and is undergoing further study.

There has been a marked decrease in snakebite vic-

Corresponding author: Dr Lawan Chanhome, QSMI, 1871 Rama IV Road, Bangkok 10330, Thailand (e-mail: trclch@md2.md.chula.ac.th). tims, with fewer than 20 annual deaths reported during recent years in Thailand. ${ }^{2}$ Snake antivenoms, nevertheless, remain essential biologicals and must be made available where the risk of envenoming still exists. ${ }^{4}$ Queen Saovabha Memorial Institute is now the only manufacturer of snake antivenoms for Thailand, Cambodia, Laos, Myanmar, Malaysia, and Singapore and is committed to exporting antivenoms to zoological gardens and research institutions around the world.

Production of snake antivenoms requires a source of species with confirmed venom, a horse farm with healthy animals that can raise antibodies to snake venoms, and a plant for the separation, purification, and pepsin digestion of equine serum. The end product is lyophilized and has a shelf life of approximately 5 years. This is a costly process and, because antivenoms are used mostly in poor tropical regions, it is not profitable and can be done only with subsidies. Several international manufacturers have discontinued production of antisera, and there is now a critical worldwide shortage of these products. ${ }^{4}$ There has also been severe encroachment into the natural environment of Thai snakes, and secure procurement of healthy animals for venom extraction is no longer ensured. This was the main reason why QSMI commenced this breeding project in 1994.

\section{Methods}

\section{COLLECTING SNAKES FOR BREEDING STOCK}

In 1994, we collected Siamese cobras (N kaouthia), Indochinese spitting cobras (Naja siamensis), king cobras 
Table 1. Variety of foods fed to each snake

\begin{tabular}{|c|c|c|c|c|c|c|c|}
\hline \multirow[b]{2}{*}{ Snakes } & \multicolumn{7}{|c|}{ Variety of foods } \\
\hline & Mice & Chicks & Frogs & Geckos & Fish* & $\begin{array}{c}\text { Nonvenom- } \\
\text { ous } \\
\text { snakest }\end{array}$ & Sausages \\
\hline \multicolumn{8}{|c|}{ Ophiophagus hannah } \\
\hline Adults & & & & & & $\mathrm{x}$ & \\
\hline Neonates & & & & & $\mathrm{x}$ & $\mathrm{x}$ & $\mathrm{x}$ \\
\hline \multicolumn{8}{|l|}{ Naja kaouthia } \\
\hline Adults & $\mathrm{x}$ & $\mathrm{x}$ & $\mathrm{x}$ & & $\mathrm{x}$ & & \\
\hline Neonates & $\mathrm{x}$ & & $\mathrm{x}$ & & $\mathrm{x}$ & & \\
\hline \multicolumn{8}{|l|}{ Naja siamensis } \\
\hline Adults & $\mathrm{x}$ & $\mathrm{x}$ & $\mathrm{x}$ & & & & \\
\hline Neonates & $\mathrm{x}$ & & & & & & \\
\hline \multicolumn{8}{|c|}{ Bungarus fasciatus } \\
\hline Adults & & & & & $\mathrm{x}$ & $\mathrm{x}$ & \\
\hline Neonates & & & & & $\mathrm{x}$ & $\mathrm{x}$ & $\mathrm{x}$ \\
\hline \multicolumn{8}{|c|}{ Bungarus candidus } \\
\hline $\begin{array}{l}\text { Adults } \\
\text { Neonates }\end{array}$ & $\mathrm{x}$ & & & & $\mathrm{x}$ & $\mathrm{x}$ & $\mathrm{x}$ \\
\hline \multicolumn{8}{|c|}{ Calloselasma rhodostoma } \\
\hline Adults & $\mathrm{x}$ & & & $\mathrm{x}$ & & & \\
\hline Neonates & $\mathrm{x}$ & & & $\mathrm{x}$ & & & \\
\hline \multicolumn{8}{|c|}{ Daboia russelii siamensis } \\
\hline Adults & $\mathrm{x}$ & & & & & & \\
\hline Neonates & $\mathrm{x}$ & & & & & & \\
\hline
\end{tabular}

* Fish $=$ eel and pieces of eel meat for feeding neonates of $O$ hannah and $B$ fasciatus. Spotted spiny eel (Macrognathus siamensis), striped snake-head fish (Channa striatus).

$\dagger$ Nonvenomous snakes $=$ adults and neonates of Enhydris sp, Elaphe radiata, and Xenochrophis piscator.

(O hannah), banded kraits (B fasciatus), Malayan kraits (Bungarus candidus), Malayan pit vipers ( $C$ rhodosto$m a$ ), and Siamese Russell vipers ( $D$ russelii siamensis) from the QSMI's snake farm. Most had been wild-caught snakes purchased from dealers in the south and central parts of Thailand. Adult males and females were added to our breeding stock in a ratio of $1: 1$ or $1: 2$. All newly captured females were checked for gravidity, and those found gravid were confined separately to lay eggs or give birth. After that, they were selected as breeding stock.

The new snakes were quarantined for at least 4 weeks. ${ }^{5}$ During this quarantine period, snakes were examined and probed to determine their health and sex. They were washed with $0.2 \%$ trichlorfon solution (Neguvon, Bayer, LeverKusen, Germany) to eradicate ectoparasites, and then they received mebendazole suspension (Benda $20 \mathrm{mg} \cdot \mathrm{mL}^{-1}$ ) at $25 \mathrm{mg} \cdot \mathrm{kg}^{-1}$ orally once every 2 weeks or Ivermectin (Ivomec, MSD AGVET, Haarlem, Netherlands) by subcutaneous injection $(0.2$ $\mathrm{mg} \cdot \mathrm{kg}^{-1}$ once every 2 weeks during the quarantine period) to eradicate endoparasites. ${ }^{6}$ Snake-eating species such as the king cobra, banded krait, and Malayan krait were given praziquantel (Droncit) at $8 \mathrm{mg} \cdot \mathrm{kg}^{-1}$ orally. This was repeated 2 weeks later to eliminate tapeworm. ${ }^{6,7}$

Snakes were fed once weekly with their food of preference, such as laboratory mice, eels, nonvenomous snakes (Enhydris sp, Elaphe radiata, Ptyas korros, etc), geckos, lizards, frogs, or chicks. Laboratory mice were the most common food items for the non-snake-eating species. They were selected to decrease the risk of endoparasitic reinfection. ${ }^{7}$ For the same reason, nonvenomous feeding snakes were given mebendazole suspension at $25 \mathrm{mg} \cdot \mathrm{kg}^{-1}$ orally once every 2 weeks before being fed to snake-eating species (Table 1$)^{7}$ 
Table 2. Bangkok's climate

\begin{tabular}{|c|c|c|c|c|c|c|c|c|c|c|c|c|c|}
\hline Variable & January & $\begin{array}{c}\text { Febru- } \\
\text { ary }\end{array}$ & March & April & May & June & July & August & $\begin{array}{c}\text { Septem- } \\
\text { ber }\end{array}$ & October & $\begin{array}{c}\text { Novem- } \\
\text { ber }\end{array}$ & $\begin{array}{c}\text { Decem- } \\
\text { ber }\end{array}$ & Annual \\
\hline \multicolumn{14}{|c|}{ Temperature, ${ }^{\circ} \mathrm{C}$} \\
\hline Maximum & 35.1 & 34.8 & 37.3 & 37.9 & 36.6 & 35.7 & 35.6 & 36.0 & 34.5 & 34.5 & 34.2 & 34.9 & 37.9 \\
\hline Minimum & 17.3 & 19.3 & 23.5 & 22.0 & 22.3 & 23.9 & 23.6 & 24.0 & 23.0 & 21.8 & 22.1 & 18.3 & 17.3 \\
\hline Mean & 27.3 & 27.4 & 29.7 & 30.6 & 29.6 & 29.6 & 28.7 & 29.2 & 28.0 & 28.7 & 28.2 & 26.3 & 28.6 \\
\hline \multicolumn{14}{|l|}{ Humidity, \% } \\
\hline Maximum & 80 & 75 & 84 & 86 & 88 & 86 & 89 & 86 & 91 & 87 & 82 & 74 & 84 \\
\hline Minimum & 33 & 21 & 36 & 37 & 46 & 47 & 47 & 49 & 47 & 43 & 45 & 30 & 21 \\
\hline Mean & 65 & 65 & 71 & 71 & 75 & 73 & 76 & 74 & 81 & 74 & 71 & 61 & 71 \\
\hline
\end{tabular}

\section{THE ENCLOSURES}

The breeding unit was separated into 2 rooms. In one, the temperature was maintained at $26^{\circ} \mathrm{C}$ to $27^{\circ} \mathrm{C}$ and at $60 \%$ to $70 \%$ humidity in the daytime, and the temperature and humidity in the night were left to vary with the seasons of Bangkok. In the other room, the temperature and humidity were left to vary with the seasons (Table 2). Fans were installed to control ventilation. Each room had windows for natural light.

The cages in the breeding units were made of wood with hard plastic mesh or clear plastic sheets for easy viewing. The wooden cages were sealed with varnish for waterproofing and measured $60 \times 60 \times 40 \mathrm{~cm}$ for breeding $C$ rhodostoma and $D$ russelii siamensis. Those for breeding $N$ kaouthia and $N$ siamensis were $100 \times$ $120 \times 50 \mathrm{~cm}$. At the beginning of the breeding program, plastic boxes were also used successfully. All boxes contained a hiding box or inverted jar, paper substrata, and a water basin filled with clean water that was changed daily. The cages were arranged so they could be cleaned easily and were disinfected with Savlon (Chlorhexidine gluconate $1.5 \% \mathrm{wt} / \mathrm{vol}$ and Cetrimide $15 \% \mathrm{wt} / \mathrm{vol}$ ) or Dettol (Chloroxylenol 5\% in isopropyl alcohol). Cleaning was carried out every day, but the disinfectant was used once a week unless a snake died in the cage or it was very dirty.

\section{THE INCUBATION UNIT}

Eggs were collected after laying. The quantity, weight, and dimension of eggs were recorded. The eggs were placed in a plastic basket which was covered with a clear plastic sheet and suspended over a bucket of water. The temperature was kept at $30^{\circ} \mathrm{C}$ to $32^{\circ} \mathrm{C}$ and the humidity at $70 \%$ to $75 \%$. The incubation period was then recorded for each clutch.

\section{NURSERY UNIT AND NEONATAL HUSBANDRY}

All neonates were moved to the nursery room and separated into plastic boxes that were ventilated by making holes on each side and lid. The box size was $27 \times 18$ $\times 15 \mathrm{~cm}$ and contained an inverted flower pot (as a hiding place), paper substrata, and a water bowl. The temperature of one part of the nursery room was kept at $28^{\circ} \mathrm{C}$ to $30^{\circ} \mathrm{C}$ during the daytime. The other part was kept at $26^{\circ} \mathrm{C}$ to $27^{\circ} \mathrm{C}$, and the temperature and humidity at night in both rooms are left to the seasons of Bangkok. Spray-misting was done as needed in both parts to ensure that the humidity remained at $60 \%$ to $70 \%$.

\section{Results}

\section{BREEDING MALAYAN PIT VIPERS (CALLOSELASMA RHODOSTOMA)}

The first successful captive mating in our breeding program was by Malayan pit vipers. Three females were paired individually with males at a ratio of 1:1 in October 1995. Each breeding pair was housed in cages with an ambient temperature of $26 \%$ to $27^{\circ} \mathrm{C}$ and a humidity of $60 \%$ to $70 \%$. They were fed normally once a week while being paired, but some refused to eat until they laid eggs. Eggs were laid on June 21, June 24, and July 13, 1996. At the same time, a new wild-caught female laid eggs on July 10, 1996 (Table 3).

In October 1996, 6 Malayan pit viper females were paired with males for 1 month, then separated to observe if females were gravid. None of these 6 females became gravid. Each breeding pair was then paired once again in April 1997. They were kept together for about 2 months, and the gravid females were then isolated until they laid eggs. This second effort was successful. Copulations were observed in 4 of 6 pairs. One pair copulated 2 times, on April 2 and April 24, 1997. We col- 
Table 3. Incubation data for Malayan pit viper (Calloselasma rhodostoma)

\begin{tabular}{|c|c|c|c|c|c|c|}
\hline $\begin{array}{c}\text { Clutch } \\
\text { no.* }\end{array}$ & $\begin{array}{l}\text { Date of laying } \\
\text { of eggs }\end{array}$ & Date of hatching & $\begin{array}{l}\text { Incubation } \\
\text { period }(d)\end{array}$ & $\begin{array}{c}\text { Clutch size } \\
\text { (no. eggs) }\end{array}$ & $\begin{array}{c}\text { No. } \\
\text { hatchlings }\end{array}$ & $\%$ hatched \\
\hline 1 & June 21, 1996 & August 2-5, 1996 & $43-46$ & 28 & 26 & 93 \\
\hline 2 & June 24, 1996 & August $4-5,1996$ & $42-43$ & 22 & 17 & 77 \\
\hline 3 & July 10, 1996 & August 15-16, 1996 & $37-38$ & 17 & 12 & 71 \\
\hline 4 & July 13, 1996 & August 18-19, 1996 & $37-38$ & 29 & 28 & 97 \\
\hline Total & & & $37-46$ & 96 & 83 & 86 \\
\hline
\end{tabular}

* Clutch 1 had 2 infertile eggs; clutch 3 had 3 infertile eggs and 2 dead fully developed fetuses; clutch 4 had 1 infertile egg.

lected 136 live hatchlings among 6 clutches-a success rate of $88 \%$ (Figure 1).

\section{BREEDING KING COBRAS (OPHIOPHAGUS HANNAH)}

A newly captive female king cobra laid 27 eggs on March 21, 1995. The eggs were separated a few days later and incubated artificially. Unfortunately, all eggs became infected with fungi after incubating for 2 weeks.

On July 10, 1996, 37 eggs were donated by a villager from Petchaboon Province, Thailand. The date of oviposition was unknown. The 37 eggs were incubated overnight, and 31 hatched successfully on July 11 . The remaining 6 unhatched eggs were incised 1 day later, and we found that all contained fully developed dead fetuses.

On March 11, 1997, copulation was observed in 1 pair of king cobras at the snake farm. The female was separated 2 weeks later and isolated in an enclosure for observation. On May 8, 1997, she was observed incubating 25 eggs. It was not known when the eggs had been laid. Fourteen eggs were dehydrated and infected with fungi. The other 11 eggs were moved to the incu-

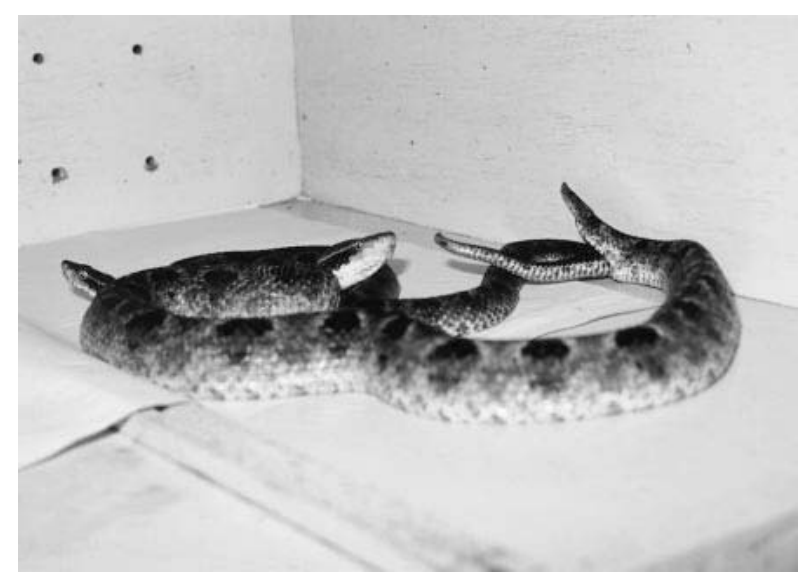

Figure 1. Malayan pit vipers copulating. bation unit. Ten of these eggs were also infected with fungi. On June 27, 1997, the remaining egg hatched. This hatchling was small, and the distal third of its vertebral column was deformed. It died on August 15 at the age of 50 days.

\section{BREEDING INDOCHINESE SPITTING COBRAS (NAJA SIAMENSIS)}

Several clutches of eggs were obtained from wild-caught Indochinese spitting cobras in 1996. These clutches were incubated with the following results: there were 8 clutches of 3 to 28 eggs each. Incubation periods ranged from 58 to 72 days, and $72 \%$ of eggs hatched, yielding a total of 80 live hatchlings.

Six pairs of Indochinese Spitting Cobras were paired in 1997. Copulation was observed in only 1 pair, but 3 clutches of eggs resulted. There was a total of 30 eggs, which, after an incubation period of 65 to 68 days, yielded a total of 21 live hatchlings (a success rate of $70 \%$ ).

\section{BREEDING SIAMESE COBRAS (NAJA KAOUTHIA)}

In 1996, eggs were obtained from gravid, wild-caught females. There were 5 clutches of 16 to 33 eggs which, with incubation periods ranging from 55 to 73 days, presented us with 64 live hatchlings (success rate of 57\%). Despite continuing efforts to breed this species in captivity, we did not succeed until 1999. We suspect that one reason for the failures was that earlier we used smaller cages (Figure 2).

\section{BREEDING BANDED KRAITS (BUNGARUS FASCIATUS)}

Our efforts to breed this species in captivity have not yet been successful. However, neonates were obtained from clutches of eggs laid by newly wild-caught females in 1996. There were 3 clutches and a total of 29 eggs, which presented us with 21 live hatchlings ( $72 \%$ success 


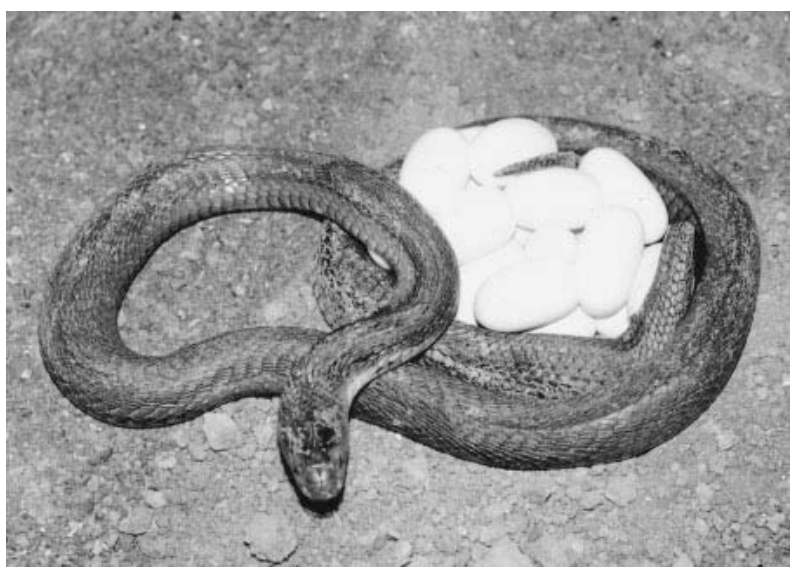

Figure 2. A Siamese cobra with a clutch of eggs.

rate) after 57 to 63 days of incubation. However, one entire clutch of 8 eggs became infected with fungus.

\section{BREEDING WHITE-LIPPED GREEN PIT VIPERS (TRIMERESURUS ALBOLABRIS)}

A female $T$ albolabris was captured on December 20, 1996. She was housed separately and produced a litter of 30 live neonates on May 2, 1997, and a second litter of 29 on April 1, 1999.

\section{BREEDING SIAMESE RUSSELL VIPERS (DABOIA RUSSELII SIAMENSIS)}

We have not been successful in breeding the Russell viper. We have, however, received litters from gravid females arriving from the wild. Data compiled on these litters are presented in Table 4 and Figure 3.

\section{THE DETERMINATION OF BREEDING SEASONS}

Times of egg laying and hatching were recorded. We then used these data for estimating breeding seasons in captivity. ${ }^{5}$ Breeding seasons for each species were esti-

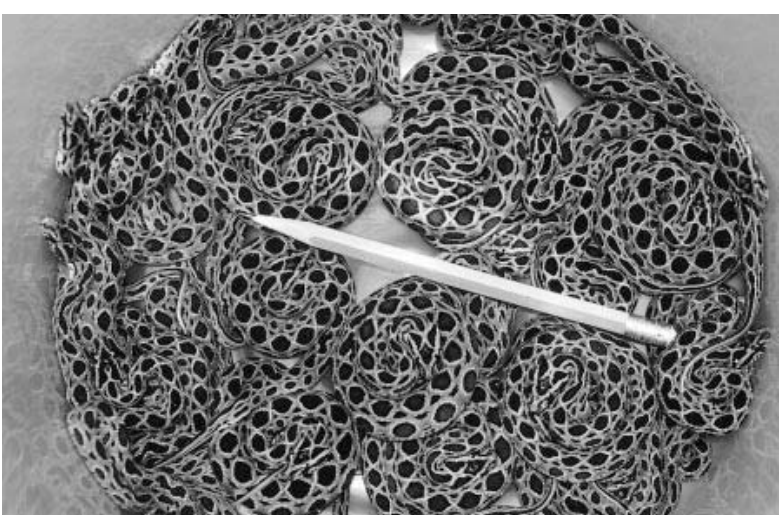

Figure 3. A litter of newly born Siamese Russell vipers.

mated by subtracting 2 months from the date of egg laying (Table 5).

\section{NEONATAL HUSBANDRY}

From late 1994 to mid-1996, all eggs and live births were by wild-caught gravid females. When females laid eggs, each clutch of eggs was separated and incubated. All neonates were transferred to the nursery unit.

Table 4 shows neonates of each species born in our initial breeding program. After the first shedding, each of the neonates was fed once a week with diets described in Table 1.

Neonates did not accept food easily. They often had to be stimulated to eat or force-fed. Stimulation was done by moving food in front of the snake with long forceps. Malayan pit viper neonates could be encouraged to accept small mouse parts such as a tail or leg. This was done by lightly touching the tip of the snake's snout or tail with the food item until a strike was induced. If this was not successful, the food items were scented with house gecko puree.

Cooked blended fish or pork with added vitamins was stuffed into pig or hen intestines to create sausages. These sausages were prepared in different sizes depending on

Table 4. Weight, total length, and first shedding of neonates (1994-96)

\begin{tabular}{|c|c|c|c|c|c|}
\hline \multirow[b]{2}{*}{ Snake } & \multicolumn{2}{|c|}{ Weight $(g)$} & \multicolumn{2}{|c|}{ Total length $(\mathrm{cm})$} & \multirow{2}{*}{$\begin{array}{l}\text { First shed } \\
\text { (d) }\end{array}$} \\
\hline & Mean $\pm S D$ & Range & Mean $\pm S D$ & Range & \\
\hline Ophiophagus hannah & $17.97 \pm 1.69$ & $12.80-20.20$ & $47.84 \pm 1.59$ & $43.00-50.00$ & $9-10$ \\
\hline Naja kaouthia & $16.37 \pm 1.34$ & $13.20-18.80$ & $33.39 \pm 1.30$ & $31.50-35.50$ & $1-15$ \\
\hline Naja siamensis & $10.09 \pm 2.09$ & $4.00-13.60$ & $27.71 \pm 2.29$ & $20.00-32.00$ & $10-15$ \\
\hline Bungarus fasciatus & $16.28 \pm 1.19$ & $14.00-19.60$ & $34.45 \pm 3.40$ & $29.00-39.50$ & $10-15(1 \mathrm{mo})$ \\
\hline Calloselasma rhodostoma & $4.96 \pm 1.03$ & $2.20-6.60$ & $16.89 \pm 0.95$ & $13.50-18.50$ & $10-15$ \\
\hline Daboia russelii siamensis & $10.32 \pm 1.31$ & $7.20-14.40$ & $27.30 \pm 1.14$ & $24.00-30.00$ & $1(3-4 h)$ \\
\hline
\end{tabular}


Table 5. Dates of breeding, egg laying, and hatching

\begin{tabular}{|c|c|c|c|c|c|}
\hline Variable & $\begin{array}{c}\text { Calloselasma } \\
\text { rhodostoma }\end{array}$ & $\begin{array}{c}\text { Naja } \\
\text { kaouthia }\end{array}$ & $\begin{array}{c}\text { Naja } \\
\text { siamensis }\end{array}$ & $\begin{array}{l}\text { Bungarus } \\
\text { fasciatus }\end{array}$ & $\begin{array}{c}\text { Ophiophagus } \\
\text { hannah }\end{array}$ \\
\hline Dates of breeding & April-May & November-January & April-May & January & January-March \\
\hline Eggs laid & June-July & December-March & June-July & March & March-May \\
\hline Eggs hatched & August & February-May & August-October & May & July \\
\hline
\end{tabular}

the size of the snakes. They have been fed successfully to king cobras and banded and Malayan kraits. ${ }^{7-9}$ We succeeded in changing the eating habits of neonates of snake- and lizard-eating species and persuaded them to accept our sausages instead. Banded krait neonates were also induced to eat long pieces of eel meat, spotted spiny eel (Macrognathus siamensis), and striped snake-headed fish (Channa striatus). Assisted and force feeding ceased when neonates accepted food items freely. Regurgitation was noted when neonates swallowed or were force-fed an excessive quantity of food. This was avoided by reducing the size of food offered. The amount of food offered was increased as the neonates grew.

Siamese Russell viper neonates were more sensitive to the captive environment than were other snakes in our program. Different prey was offered after the first shed, but most refused to eat. They had to be force-fed once weekly with small pieces of beef heart and pieces of adult and suckling mice. When these neonates were approximately 3 months old, they developed signs of respiratory disease, and many died suddenly without prior evidence of illness.

During the first year of this project, when neonates were kept together in the same box, cannibalism was occasionally observed among $D$ russelii siamensis, $C$ rhodostoma, and $N$ kaouthia. This had also been observed in prior reports. ${ }^{10}$

\section{DELAYED FERTILIZATION}

Delayed fertilization and delayed implantation have been previously described in snakes. ${ }^{11}$ We noted 2 episodes of delayed fertilization. In 1994, a Malayan pit viper produced 17 fertilized eggs 9 months after her last contact with a male. ${ }^{12}$ More recently, delayed fertilization was also observed in $T$ albolabris. This snake was captured on December 20, 1996, near Bangkok. It delivered 30 newborns on May 2, 1997, 134 days after being kept isolated. On April 1, 1999, 29 newborns were again discovered in her single cage. The body size and weight of the second brood was smaller than those of the first. She had never been bred or cohabited with any males in captivity until delivery of the 2 broods.

\section{CURRENT STATUS OF BREEDING PROGRAM}

Continuing experimentation and more experience led to some success in more recent breeding efforts. Table 6

Table 6. Hatchling outcomes from 1996 to 2000

\begin{tabular}{|c|c|c|c|c|c|}
\hline Species & $1996 *$ & 1997 & 1998 & 1999 & 2000 \\
\hline Naja kaouthia $\dagger$ & $64(57)$ & $80(74)$ & $53(91)$ & $94(85)$ & $26(100)$ \\
\hline Naja siamensis & $80(72)$ & $21(70)$ & $6(35)$ & $62(81)$ & $\cdots$ \\
\hline Naja sumatrana $\S$ & $\cdots$ & $\cdots$ & $\cdots$ & $\cdots$ & $3(100)$ \\
\hline Ophiophagus hannah\| & $31(84)$ & $\cdots$ & $\cdots$ & $5(42)$ & $24(96)$ \\
\hline 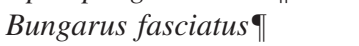 & $21(72)$ & $\cdots$ & $\cdots$ & $6(55)$ & $12(41)$ \\
\hline Bungarus candidus & $\cdots$ & $\cdots$ & $\cdots$ & $3(60)$ & $8(73)$ \\
\hline Calloselasma rhodostoma\# & $83(86)$ & $136(88)$ & $26(38)$ & $96(73)$ & $114(89)$ \\
\hline
\end{tabular}

\footnotetext{
* Number in parentheses is percentage of success rate.

$\uparrow$ Naja kaouthia: in 1999, 37 hatchlings were from captive breeding.

\$ Naja siamensis: all were from captive breeding since 1997.

$\S$ Naja sumatrana: we first had success in breeding this species in captivity (plastic box).

IIOphiophagus hannah: all were from captive breeding since 1999.

I Bungarus fasciatus, B candidus: eggs were from wild-caught females.

\# Calloselasma rhodostoma: all were from captive breeding since 1997.
} 
shows outcomes from 1996 to 2000 . This enabled the snake farm to become almost completely independent of snake dealers.

\section{Conclusion}

We have been successful in captive breeding of Malayan pit vipers and Indochinese spitting cobras but only moderately successful in the breeding of king cobras. Siamese cobras were first successfully bred in 1999, but we have not yet succeeded in breeding kraits, white-lipped pit vipers, or Siamese Russell vipers.

With the exception of Siamese Russell vipers, we have been successful in raising neonates. With each clutch and litter we have learned new techniques in neonate husbandry and have improved our survival record. For instance, we have learned more about individual food preferences and methods of inducing reluctant feeders to accept food. We are optimistic that we will be able to expand our captive breeding program further.

\section{Acknowledgments}

This project could not have succeeded without the devoted technical help of Pairin Thongkomtae, Viroon Thongkomtae, Prayoon Niwornrum, Pan Chimnoung, and Sondorn Pumsiri. The authors are grateful to Professors Visith Sitprija (Director of QSMI), Narongsak Chaiyabutr (Dean, Faculty of Veterinary Science), and Dr Montri Chiobumroongkrait for their help and encouragement. Financial support came from the Thai Red Cross Society.

\section{References}

1. Chanhome L, Cox MJ, Wilde H, Jintakune P, Chaiyabutr N, Sitprija V. Venomous snake bite in Thailand. I. Medically important snakes. Mil Med. 1998;16:310-317.

2. Pochanugool C, Wilde H, Bhanganada K, et al. Venomous snake bite in Thailand. II. Clinical experience. Mil Med. 1998;163:318-323.

3. Khow O, Pakmanee N, Chanhome C, et al. Cross-neutralization of Thai cobra (Naja kaouthia) and spitting cobra (Naja siamensis) venoms by Thai cobra antivenom. Toxicon. 1997;35:1649-1651.

4. Wilde H, Thipkong P, Sitprija V, et al. Heterologous antisera are essential biologicals: perspective of a worldwide crisis. Ann Intern Med. 1996;125:233-236.

5. Ross RA. The Reproductive Husbandry of Pythons and Boas. Stanford, CA: Institute for Herpetological Research; 1990:29-47.

6. Klingenberg RJ. Understanding Reptile Parasites: A Basic Manual for Herpetoculturists and Veterinarians. Special ed. Lakeside, CA: Advanced Vivarium Systems; 1993:250.

7. Evans GH. Food of krait. J Bombay Nat Hist Soc. 1904; 14:599.

8. Biswas S. A note on the food habits of the banded krait. Hamadryad. 1984;9:10.

9. Slowinski JB. The diet of kraits (Elapidae: Bungarus). Herp Rev. 1994;25:51-53.

10. Tare TG, Renapurkar DM. Observation on cannibalism in cobra Naja naja in captivity. Snake. 1991;23:42-43.

11. Schuett GW, Fernandez PJ, Chiszar D, Smith HM. Fatherless sons: a new type of parthenogenesis in snakes. Fauna. 1998;3:20-25.

12. Chanhome L. Delayed fertilization, embryonic morphology and neonatal husbandry in Malayan pit viper, Calloselasma rhodostoma. The Snake. 1998;28:96-98. 